\title{
Böbreğin Mikst Epitelyal ve Stromal Tümörü (MEST): iki Nadir Olgu Sunumu
}

\section{Mixed Epithelial and Stromal Tumor of the Kidney: Two Rare Case Reports}

\author{
Dr. Serdar Çelik1, Dr. Kaan Çömez1, Dr. Ozan Bozkurt11, Dr. Ömer Demir¹, Dr. Burçin Tuna22, Dr. Güven Aslan1, \\ Dr. Kutsal Yörükoğlu2 ${ }^{2}$ Dr. Mustafa Seçil3, Dr. IIhan Çelebi ${ }^{1}$ \\ ${ }^{1}$ Dokuz Eylül Üniversitesi Tıp Fakültesi, Üroloji Anabilim Dalı, Izmir, Türkiye \\ 2Dokuz Eylül Üniversitesi Tıp Fakültesi, Patoloji Anabilim Dalı, Izmir, Türkiye \\ ${ }^{3}$ Dokuz Eylül Üniversitesi Tıp Fakültesi, Radyoloji Anabilim Dalı, Izmir, Türkiye
}

\section{Özet}

Böbreğin mikst epitelyal ve stromal tümörleri (MEST), nadir gözlenen tümörlerdir. Santral yerleşimli solid-kistik lezyonlar şeklinde görüntülenirler. $\mathrm{Bu}$ yüzden malign tümörlerden ayrımı zordur. Etiyolojisinde hormonoterapiler sorumlu tutulmaktadır. Bu nedenle kadınlarda daha fazla gözlenmektedirler. Cerrahi sınır pozitifliği ve biyopsi tümör nüksünü arttırmaktadır. Bu tümörlerde kesin tanı ve tedavi komplet cerrahi eksizyondur. (Üroonkoloji Bülteni 2014;13:187-189)

Anahtar Kelimeler: Böbrek tümörü, hormonoterapi, kistik renal kitle, mikst epitelyal ve stromal tümör (MEST)

\begin{abstract}
Summary
Mixed epithelial and stromal tumors of the kidney (MEST) are rare tumors. These tumors appear solid-cystic and central localized in the kidney. Therefore it is difficult to differentiate them from malign tumors. Hormonotherapy are responsible for tumor etiology. For this reason, they are more frequently observed in women. Positive surgical margins and biopsy increases the recurrence of tumors. Definitive diagnosis and treatment is complete surgical excision in these tumors. (Bulletin of Urooncology 2014;13:187-189)
\end{abstract}

Key Words: Kidney tumor, hormonotherapy, cystic renal mass, mixed epithelial and stromal tumor (MEST)

\section{Giriş}

Mikst epitelyal ve stromal tümörler (MEST), çok nadir gözlenen kompleks, kistik-solid, epitelyal ve stromal elemanlar içeren neoplazilerdir $(1,2)$. MEST patogenezi; tam olarak aydınlatılamamış olup, multidifferansiasyon özelliği olan fetal primitif mezenkimal doku ya da metanefrik blastemin hormonal etki ile böbrek içerisinde büyüyerek kitlesel lezyon oluşturmasına dayandırılmıştır $(3,4)$. Etiyolojisinde, kadınlarda uzun dönem östrojen maruziyeti, erkeklerde ise prostat adenokarsinomu nedenli uygulanan hormonoterapiler sorumlu tutulmaktadır. Bu yüzden kadınlarda erkeklere oranla daha fazla gözlenmektedir (5). Malign tümörlerden ayrımı önemli olan bu tümörlerin kesin tanı ve tedavisi ancak cerrahi eksizyon ile mümkündür (6).

Bu yazıda hormonal tedavi öyküsü olmayan, yan ağrısı nedenli yapılan tetkiklerinde böbrekte kistik kitlesel oluşum saptanan ve cerrahi tedavi sonrası patolojileri MEST olarak raporlanan iki kadın olgu değerlendirildi.

\section{Olgu Sunumları}

\section{Olgu 1}

Sağ yan ağrısı nedenli kliniğimize başvuran 41 yaşında kadın hasta değerlendirildi. Menstrüel siklusu normal olan ve hormon replasman tedavisi almayan hastanın özgeçmişinde herhangi bir özellik mevcut değildi. Ultrasonografik incelemesinde sağ böbrekte kistik lezyon saptanan hastaya abdominal manyetik rezonans (MR) görüntüleme tetkiki yapıldı. MR'sinde sağ böbrek orta kesim lateralde, $7 \mathrm{~cm}$ kistik alanlar içeren kitlesel lezyon saptandı (Resim 1A ve 1B). Eksplorasyon kararı alınan hastaya flank insizyon ile girildi. Eksplorasyonda sağ böbrek orta kesimde santrale uzanımı olan kistik kitlesel lezyon saptanan hastaya sağ açık radikal nefrektomi yapıldı. Kitle böbrek ile birlikte enblok olarak çıkartıldı. Makroskopik incelemede böbreğin santral bölümünden ekspansil gelişim gösteren çok sayıda kist ve solid alanlar içeren tümör gözlendi (Resim 1C). Mikroskopik incelemede tümörün nefrojenik adenoma benzer şekilde daha çok kistler ve tubuler yapılardan

Yazışma Adresi/ Address for Correspondence: Dr. Serdar Çelik, Dokuz Eylül Üniversitesi Tıp Fakültesi, Üroloji Anabilim Dalı, İzmir, Türkiye E-posta: serdarcelik84@hotmail.com Gelis Tarihi/Received: 01.09.2014 Kabul Tarihi/Accepted: 04.09.2014 


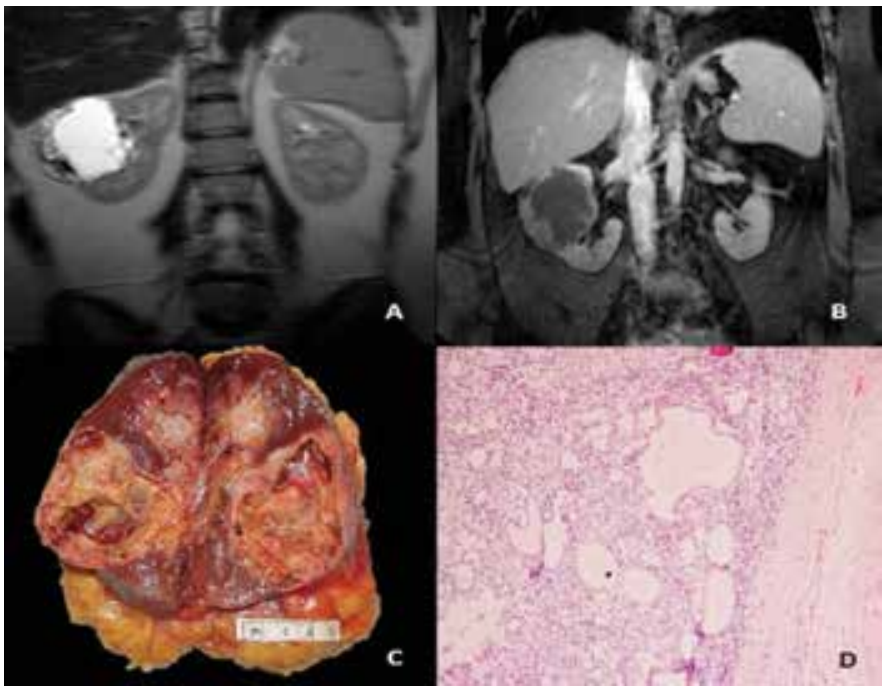

Resim 1. A-B) Koronal T2 ve post-kontrast yağ baskılı T1 görüntülerde sağ böbrek orta kesim lateralde yerleşmiş, düzensiz duvar yapısına sahip kistik alanlardan oluşan kitle görülüyor. C) Santral yerleşimli, kistik ve solid alanlar içeren tümörün makroskopik görünümü. D) Resim 1C'deki tümörün mikroskopisi: Kistik ve tubuler yapılar ile iğsi stromal hücreler (Hematoksilen\&Eozin, x100)

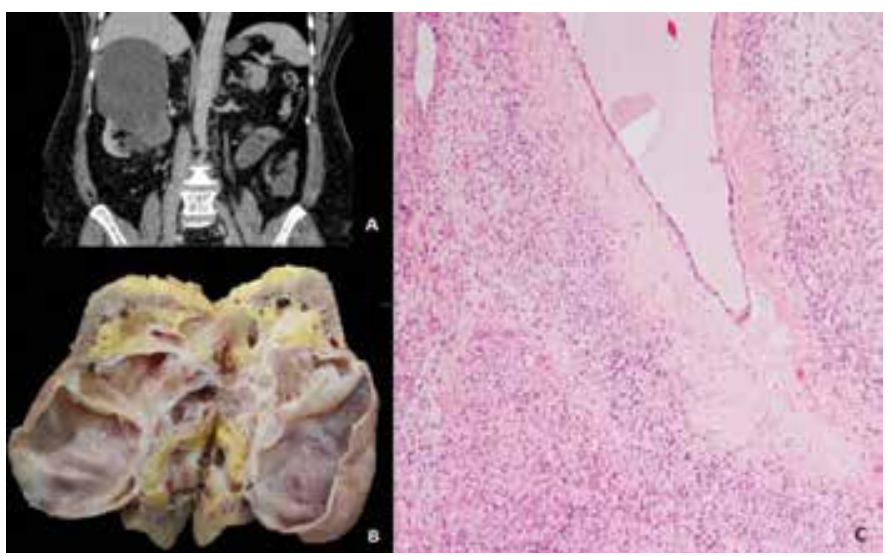

Resim 2. A) Koronal reformat post-kontrast BT görüntüsünde sağ böbrekte, septasyonlar içeren ve solid bileşeni kontrastlanan kistik iç yapıda tümör izleniyor. B) Santral yerleşimli, kistik ve solid alanlar içeren, renal sinüs ve pelvise dayanmış tümörün makroskopik görünümü. C) Resim 1 B'deki tümörün mikroskopisi: Kabara çivisi hücrelerin döşediği kistik yapılar ve hyalinize alanlar içeren sellüler stromal komponent (Hematoksilen\&Eozin, x100)

oluştuğu, arada iğsi bir stromanın varlığı izlendi (Resim 1D). İmmunohistokimyasal olarak; Sitokeratin 7 ve 8 ile boyanan epitelyal komponent ve aktin, desmin, vimentin, kalretinin, östrojen (ER) ve progesteron reseptörü (PR) ile boyanan stromal komponent içeren olgu mikst epitelyal ve stromal tümör (MEST) olarak raporlandı. Tümör cerrahi sınırı negatif olan hastada peroperatif ve postoperatif herhangi bir komplikasyon izlenmedi. Hasta postoperatif 5. yılında poliklinik kontrolünde olup sorunsuz bir şekilde görüntülemesinde stabil bulgular ile izlenmektedir.

\section{Olgu 2}

Yine sağ yan ağrısı nedenli başvuran 61 yaşında kadın hastanın özgeçmişinde herhangi bir özellik yoktu. Hasta postmenopozal dönemde olup hormon replasman tedavisi almıyordu. Daha önceki menstrüel siklus dönemleri de normal olarak bildirilen hastanın ultrasonografi tetkikinde sağ böbrekte kistik kitlesel lezyon saptanması üzerine hastaya abnominal bilgisayarlı tomografi (BT) tetkiki yapıldı. BT'de sağ böbrek üst pol ve orta kesimi kaplayan, septasyonlar içeren ve solid bileşeni kontrastlanan $14 \mathrm{~cm}$ kistik kitlesel lezyon mevcut (Resim 2A) olan hastaya flank insizyon ile sağ açık radikal nefrektomi yapıldı. Hastada peroperatif ya da postoperatif herhangi bir komplikasyon gözlenmedi. Makroskopik olarak tümör santral yerleşimli ve kistik özellikteydi, solid alanların az olduğu izlendi (Resim 2B). Mikroskopik incelemede yer yer hyalinize, yer yer sellüler iğsi hücreli bir stromada kabara çivisi özelliğinde bir epitelin döşediği kistik yapılardan oluşan tümör gözlendi (Resim 2C). İmmunohistokimyasal olarak epitelyal komponent sitokeratin ile ve stromal komponent vimentin, ER, PR ve aktin ile boyandı. Bu bulgular ile MEST tanısı konulan ve cerrahi sınırı salim olan hasta postoperatif 3. yılında poliklinik kontrolünde stabil bir şekilde izlenmektedir.

\section{Tartışma}

Böbreğin epitelyal ve stromal tümörleri kistik nefromadan, malign mikst epitelyal stromal tümörlere kadar geniş bir spektrum gösterirler (7). MEST, epitelyal ve stromal komponetleri barındıran solid-kistik neoplazilerdir. Kadınlarda erkeklere oranla 6-10 kat daha fazla gözlenirler. Ortalama görülme yaşı 46'dır. $\mathrm{Bu}$ tümörler genellikle yan ağrısı, hematüri ve kitle etkisi ile semptom verirler. Fakat \%25 hastada rastlantısal olarak saptanırlar $(1,5,8,9)$. İki olgumuzda da semptom olarak sağ yan ağrısı mevcuttu. Bu tümörler genellikle hormon replasman tedavisi alan kadın hastalarda gözlenmektedir. Literatürde prostat kanseri nedenli hormonoterapi gören erkek olgular da bulunmaktadır (5). İki olgumuzun da cinsiyeti kadın olup her ikisinde de hormon replasman öyküsü ya da menstrüel siklus düzensizlikleri mevcut değildi.

Görüntüleme yöntemlerinde genellikle santral yerleşimli ya da korteksten protrüde, Bosniak tip 3-4 kistik kitlesel lezyon şeklinde gözlenirler $(10,11)$. Görüntüleme yöntemleri ile malign tümörlerden ayrımı zordur. Ayrımında kist içeren nefroblastom, multiloküler kistik renal hücreli karsinom, epitelyal kist içeren anjiomyolipom ve sinoviyal sarkom gibi tümörler bulunur (1). Her iki olguda da abdominal $M R$ ve BT görüntülemeleri incelenmiş olup, sağ böbrekte $7 \mathrm{~cm}$ ve $14 \mathrm{~cm}$ 'lik Bosniak tip 3-4 uyumlu kistik kitlesel lezyonlar vardı. Bu bulgular ile malignbenign ayrımı yapılamayan her iki hastaya da eksplorasyon kararı alındı. Her iki olguda da tümör yerleşiminin santral ve tümör boyutunun büyük olmasından dolayı açık radikal nefrektomi uygulandı.

$\mathrm{Bu}$ tümörlerin patolojik incelemesinde bifazik, epitelyal ve stromal elemanlar mevcut olup, mikroskopisinde makrokist, mikrokist, tübül ve ovaryan benzeri stroma gözlenir.

Genellikle stromal komponent ER, PR, vimentin, aktin ve desmin eksprese ederken, epitelyal komponent ise sitokeratin 7, pansitokeratin, sitokeratin $\mathrm{AE} 1 / 3$ ve kalretinin ile pozitif boyanır $(1,2,9,12)$. 
Ayrıca bu tümörlerde operasyon öncesi kitle biyopsisi rekürrensi arttırdığı için önerilmemektedir (13). Kür cerrahi eksizyon ile mümkün olmakla birlikte, radikal ya da parsiyel nefrektomi uygulanabilmektedir. Her iki cerrahi yöntemde de önemli olan nüks riskinin azaltılması amaçlı cerrahi sınır pozitifliğinin önlenmesidir. Bu da ancak dikkatli cerrahi rezeksiyon ile olasıdır $(2,14)$. Aynı şekilde iki olgumuza da radikal nefrektomi uygulanmış olup, cerrahi sınır negatifliği sağlanmıştır.

Kistik nefroma ve MEST genellikle benign davranışlı tümörlerdir. Fakat malign özellikler gösteren tümörler de raporlanmıştır $(1,7)$. Malign tümörlerde sarkomatoid differansiasyon saptanmış olup, bu hastalarda indifferansiye sarkom, leiomyosarkom, rabdomyosarkom, pleomorfik sarkom ve malign mesenkimoma gözlenebilmektedir (15). Malign stromal komponentler içeren olgularda lokal nüks gözlenmiştir. MEST olgularının bir kısmında da karsinomatöz ve berrak hücreli transformasyon raporlanmıştır $(8,16)$. Özellikle hormonoterapi alan prostat adenokarsinomlu erkek olgularda malign özellikler gösteren MEST açısından dikkatli olunması önerilmiştir (7). İki olgu da da malignite potansiyeli açısından hastalar takibe alınmıştır. İlk olguda 5 yıl, ikinci olguda 3 yıllık takip süresinde maligniteyi düşündürecek herhangi bir metastaz ya da nüks gözlenmemiştir. Bu bulgular doğrultusunda ilk planda benign karakterli tümör düşünülen iki olguda da izleme devam edilmektedir.

\section{Sonuç}

MEST görüntüleme yöntemleriyle malign tümörlerden ayrımı mümkün olmayan, böbrek biopsisinin ve cerrahi sınır pozitifliğinin nüksü arttırdığı, kesin tanı ve tedavisinin cerrahi eksizyon olduğu malign differansiasyon potansiyeli olan ve etiyolojisinde çoğunlukla hormonal tedavilerin yer tuttuğu, çoğunlukla benign, kistik böbrek tümörlerdir.

\section{Çıkar çatışması: Yazarlar bu makale ile ilgili olarak herhangi bir çıkar çatışması bildirmemişlerdir.}

\section{Kaynaklar}

1. Montironi R, Mazzucchelli R, Lopez-Beltran A, et al. Cystic nephroma and mixed epithelial and stromal tumour of the kidney: opposite ends of the spectrum of the same entity? Eur Urol 2008;54:1237-1246.
2. Mohanty SK, Parwani AV. Mixed epithelial and stromal tumors of the kidney: an overview. Arch Pathol Lab Med 2009;133:1483-1486.

3. Turbiner ], Amin MB, Humphrey PA, et al. Cystic nephroma and mixed epithelial and stromal tumor of kidney: a detailed clinicopathologic analysis of 34 cases and proposal for renal epithelial and stromal tumor (REST) as a unifying term. Am J Surg Pathol 2007;31:489-500.

4. Buritica C, Serrano M, Zuluaga A, et al. Mixed epithelial and stromal tumour of the kidney with luteinised ovarian stroma. J Clin Pathol 2007; 60:98-100.

5. Adsay NV, Eble JN, Srigley JR, et al. Mixed epithelial and stromal tumor of the kidney. Am. J. Surg. Pathol. 2000;24:958-970.

6. Shuo Zheng, Hai Chao Yuan, Liang Ren Liu, et al. Mixed epithelial and stromal tumor of the kidney. Journal of Medical Sciences 2013;29:280-283.

7. Suzuki T, Hiragata S, Hosaka K, et al. Malignant mixed epithelial and stromal tumor of the kidney: report of the first male case. Int J Urol 2013;20:448-450.

8. Jevremovic D, Lager DJ, Lewin M. Cystic nephroma (multilocular cyst) and mixed epithelial and stromal tumor of the kidney: a spectrum of the same entity? Ann Diagn Pathol 2006;10:77-82.

9. Portier BP, Hansel DE, Zhou M. Mixed epithelial and stromal tumor of the kidney. J Urol 2009;181:1879-1880.

10. Lang N, Li J, Liu JY, et al. Mixed epithelial and stromal tumor of the kidney: an analysis of multidetector computed tomography manifestations and clinicopathologic findings. I Comput Assist Tomogr 2010;34:177-181.

11. Sahni VA, Mortele KJ, Glickman J, et al. Mixed epithelial and stromal tumour of the kidney: imaging features. BJU Int 2010;105:932-939.

12. Antic T, Perry KT, Harrison K, et al. Mixed epithelial and stromal tumor of the kidney and cystic nephroma share overlapping features: reappraisal of 15 lesions. Arch Pathol Lab Med 2006;130:80-85.

13. Jung SJ, Shen SS, Tran T, et al. Mixed epithelial and stromal tumor of kidney with malignant transformation: report of two cases and review of literature. Hum Pathol 2008;39:463-468.

14. Yap YS, Coleman M, Olver I. Aggressive mixed epithelialestromal tumour of the kidney treated with chemotherapy and radiotherapy. Lancet Oncol 2004;5:747-749.

15. Svec A, Hes O, Michal M, Zachoval R. Malignant mixed epithelial and stromal tumor of the kidney. Virchows Arch 2001;439:700-702.

16. Omar AM, Khattak AQ, Lee JA. Cystic renal cell carcinoma arising from multilocular cystic nephroma of the same kidney. Int Braz J Urol 2006;32:187-189. 